\title{
PENELITIAN PENGGUNAAN MINAREX PERTAMINA SEBAGAI MINYAK PELUNAK KOMPON KARET UNTUK SOL SEPATU KANVAS
}

Oleh : Sofyan Karani, Prayitno, Sri Bandi, Sri Budiasih

\section{ABSTRACT}

The objective of the research is to use minarex, by product of Pertamina, as a softener in making rubber sole compound for canvas shoes. The formula of the compound applied fuor kinds of minarex, namely minarex A, B, C and D with variation $2-8 \mathrm{phr}$. The mastication and mixing processes used two roll mill machine and the compound was vulcanized at $150^{\circ} \mathrm{C}$, at the pressure $150 \mathrm{~kg} /$ $\mathrm{cm}^{2}$ and 10 minutes curing time. The comformityt of softener, minare, is excellent and no oil exist to the surface of the vulcanized compound. The property of the vulcanized compound fulfilled all the quality requirements of SNI 0778-89. $\mathrm{A}$ and SNI 1844-90-A for canvas shoe rubber sole, except abrassion for sport shoe (max. $1.00 \mathrm{~mm}^{3} / \mathrm{kgm}$ compared with the result of the test, $1.52-2.35 \mathrm{~mm}^{3}$ / $\mathrm{kgm})$. Data analysed proves the to kinds of minarex to influence all properties in rubber compounds. While treatmant of minarex to influince the the properties of elongation at break, permanent set and hardness. The type of minarex to influince properties of the tear strength, abrassion and density to rubber compound.

\section{INTISARI}

Penelitian ini bertujuan untuk menggunakan minarex Pertamina sebagai bahan pelunak dalam pembuatan kompon karet untuk sol sepatu kanvas. Formula kompon menggunakan empat jenis minarex yaitu minarex A, B, C dan $\mathrm{D}$ dengan variasi antara 2 - $8 \mathrm{phr}$. Pencampuran menggunakan giling karet terbuka dan kompon divulkanisasi pada suhu $150^{\circ} \mathrm{C}$, tekanan $150 \mathrm{~kg} / \mathrm{cm}^{2}$ dan waktu 10 menit. Tingkat kecocokan bahan pelunak minarex sangat baik, tidak terjadi pengeluaran minyak ke permukaan kompon dan vulkanisat kompon. Sifat vulkanisat memenuhi semua persyaratan mutu dalam SNI 0778-89-A dan SNI 1844-90-A untuk sol karet sepatu kanvas, kecuali syarat mutu ketahanan kikis sol sepatu untuk olah raga maks. $1,00 \mathrm{~mm}^{3} / \mathrm{kgm}$ dibandingkan dengan hasil 
i kikis vulkanisat yaitu antara $1,52-2,35 \mathrm{~mm}^{3} / \mathrm{kgm}$. Hasil analisa data uji meunjukkan jenis minrex mempengaruhi semua sifat fisis kompon yang di ujikan. edangkan sifat perlakuan minarex mempengaruhi perpanjangan putus, perpaningan tetap dan kekerasan. Type minarex mempengarui ketahanan jenis dan etahanan sobek kompon karet.

\section{PENDAHULUAN}

Dalam pembuatan kompon karet dibutuhkan bahan baku berupa karet lam dan bahan pembantu lainnya yang berupa bahan kimia yaitu : bahan pengi, aktifator, accelerator, softener, anti oksidan, vulkanisator dan bahan kimia innya.

Pencampuran karet dengan bahan pembantu menggunakan mesin pengiling dengan tujuan untuk mendapatkan campuran yang homogen. Karet menth merupakan bahan yang ulet, kuat dan liat maka dalam proses pencampuran an pengolahan memerlukan pelunak dan panas serta tenaga yang intensif seingga pencampuran bahan pembantu lebih mudah dan dalam waktu yang lebih ingkat dalam proses pencampuran. Bahan pelunak adalah bahan yang berfunguntuk memudahkan pencampuran bahan pengisi dan meningkatkan penyearan bahan pengisi dalam kompon karet. Sehingga proses pencampuran dapat ilakukan pada suhu relatif rendah untuk menghindari terjadinya schorsing praulkanisasi $(3,4)$

Sebagian besar minyak pelunak (softener) yang digunakan dalam industri aret dalam negeri masih di impor dan kebutuhan setiap tahun terus meningkat esuai dengan perkembangan industri perkaretan di Indonesia. Didapat beberaa merek yang memenuhi pasaran dalam negeri, yaitu : Dutrex buatan Sheel, Ku ong buatan Korea, Gulf Processing oil dan Mobil sol buatan Amerika Serikat 1)

Untuk mengantisipasi hal tersebut dan dalam usaha menaikkan nilai ambah produk ekstrak dan mengoptimalkan operasi kilang Pertamina. Pertaina telah menghasilkan dan memasarkan dua produk baru yang dihasilkan leh kilang minyak Unit Pengolahan IV Pertamina di Cilacap, Yaitu : 1). miyak pelunak aromatik atau Aromatic Processing Oil dengan merek dagang IINAREX, Minarex yang di produksi Pertamina ada empat jenis yaitu ; Minaex A, Minarex B, Minarex C dan Minarex D 2). minyak pelunak parafinik atau araffinic Processing Oil dengan merek dagang PARAFFINIC OIL. Paraffinic

Majalah Barang Kulit, Karet dan Plastik oil yang diproduksi Pertamina ada dua jenis yaitu : PARAFFINIC 60 dan PARAFFINIC 95 (2)

Ada tiga golongan minyak pelunak yang berasal dari pengolahan minyak bumi, yaitu : minyak parafinik, minyak naftanik dan minyak aromatik, dimana masing-masing golongan mempunyai pengaruh yang spesifik pada kompon dan barang jadinya (5)

Dalam rangka penerapan penggunaan minyak pelunak hasil Pertamina dalam industri barang karet dan plastik, Pertamina telah melakukan kerja sama penelitian antara Dinas Pengendalian Mutu Petrokimia Pertamina Jakarta dengan Balai Besar Penelitian dan Pengembangan Industri Barang Kulit, Karet dan Plastik Yogyakarta. Salah satu penelitiannya adalah Penggunaan minarex Pertamina sebagai minyak pelunak (softener) dalam pembuatan kompon karet untuk sol sepatu kanvas.

\section{BAIIAN DAN METODA}

1. Bahan

Bahan minarex yang digunakan untuk mengamati pengaruh penggunaannya dalam kompon karet sebagai bahan pelunak untuk sol sepatu kanvas ada 4 jenis dan 2 type yaitu :

1. Jenis minarex $A$

- type minarex A. 2

- type minarex A. 3

2. Jenis Minarex B

- type minarex B. 2

- type minarex B. 3

3. Jenis minarex $C$

- type minarex C. 2

- type minarex C. 3

4. Jenis minarex D

- type minarex D. 2

type minarex D. 3

dimana typical properties minarex untuk masing-masing jenis dapat dilihat dalam tabel 7

Formula yang digunakan dalam penelitian ini dapat dilihat dalam tabel 1, dimana variasi bahan pelunak minarex dalam kompon untuk masingmasing jenis dan type adalah 2, 5 dan 8 perseratus berat karet (phr). 
Tabel 1. Formula kompon sol sepatu untuk tiap type minarex

\begin{tabular}{|r|l|r|r|r|}
\hline \multirow{2}{*}{ No. } & \multicolumn{1}{|c|}{ B a h a n } & \multicolumn{3}{|c|}{ Perlakuan } \\
\cline { 3 - 5 } & & I (phr) & II (phr) & III (phr) \\
\hline 1 & Pale Crepe & 80,0 & 80,0 & 80,0 \\
2 & SBR & 20,0 & 20,0 & 20,0 \\
3 & Kalsium Karbonat & 30,0 & 30,0 & 30,0 \\
4 & Aluminium silikat & 40,0 & 40,0 & 40,0 \\
5 & Zink oksida & 4,0 & 4,0 & 4,0 \\
6 & Asam stearat & 1,5 & 1,5 & 1,5 \\
7 & Tin oksida & 1,0 & 1,0 & 1,0 \\
8 & Zat warna & 0,5 & 0,5 & 0,5 \\
9 & Minarex & $(2,0)$ & $(5,0)$ & $(8,0)$ \\
10 & Anti oksidan & 1,0 & 1,0 & 1,0 \\
11 & MBT & 0,7 & 0,7 & 0,7 \\
12 & MBTS & 0,4 & 0,4 & 0,4 \\
13 & TMT & 0,5 & 0,5 & 0,5 \\
14 & Sulpur & 2,5 & 2,5 & 2,5 \\
\hline
\end{tabular}

Metoda

Proses pencampuran bahan kimia dalam pembuatan kompon dilakukan dengan menggunakan mesin penggiling karet terbuka (two roll mill) pada suhu giling sekitar $70^{\circ} \mathrm{C}$ sebanyak 36 kali komponding.

Setelah pembuatan kompon selesai, kompon di aging selama 24 jam dalam ruangan kondisi. Tahap berikutnya dilakukan proses vulkanisasi dengan kondisi proses suhu $150^{\circ} \mathrm{C}$, tekanan $150 \mathrm{~kg} / \mathrm{cm}^{2}$ dan waktu 10 menit untuk mengetahui sifat-sifat kompon karet.

Pengujian sifat fisis kompon dilakukan terhadap sifat kekuatan tarik, perpanjangan putus, perpanjangan tetap $50 \%$, kekuatan sobek, kekerasan, bobot jenis dan ketahanan retak lentur sesuai dengan persyaratan uji menurut SNI 0778-89-A; Sol karet cetak untuk masing-masing pengujian. Hasil uji vulkanisat dari masing-masing kompon pada formula dibandingkan dengan persyaratan mutu sol sepatu yang terdapat dalam SNI 0778-89-A; Sol karet cetak untuk sepatu kanvas dan SNI 1844-90-A; Sol karet cetak sepatu olah raga lihat tabel 6. Sedangkan CNS 68531-742.S.2010; Testing standart for shoes (canvas high tops) dan KS.N 6522-74; Canvas shoes with rubber soles digunakan sebagai pembanding hasil uji selanjutnya lihat tabel 7 .

\section{HASIL DAN PEMBAHASAN}

Untuk lebih mengetahui sifat kemampuan kompon yang menggunakan minarex Pertamina sebagai bahan pelunak, maka perlu dilakukan pengamatan secara organoleptis selama proses pembuatan kompon dan proses vulkanisasi kompon serta uji sifat fisis vulkanisat kompon. Sehingga daya guna kompon dapat tergambar dengan jelas jika dibandingkan dengan persyaratan mutu kompon yang ada.

1. Sifat kenampakan kompon (organoleptis)

Dari 72 kali proses komponding yang dilaksanakan dalam penelitian yang menggunakan minarex sebagai bahan pelunak, pencampuran bahan pelunak cukup baik dan tidak terjadi pengeluaran minyak kepermukaan kompon dan vulkanisat kompon. Warna kompon dan vulkanisat sesuai dengan warna pigmen yang digunakan dengan penambahan titan oksida 1,0 phr. Menurut Krisha-1980, tingkat kecocokan antara minyak pelunak dengan karet sangat tergantung dari kesamaan daya kohesi karet dengan minyak. Semakin baik tingkat kecocokan antara minyak pelunak dengan karet, semakin banyak pula pelunak tercampur dalam karet. Bila pelunak tidak cocok dengan karet, minyak pelunak akan merembes keluar ke permukaan dan menyebabkan permukaan kompon akan sticky (mudah lepas bila ditempelkan satu sama lain), sehingga daya lengket akan berkurang bila ditempelkan pada bahan lain.

Dengan demikian dapat dikatakan pencampuran minyak pelunak minarex Pertamina dengan karet mempunyai tingkat homogenitas pencampuran yang baik.

2. Sifat fisis vulkanisat kompon.

Hasil uji sifat fisis Vulkanisat kompon untuk masing-masing penggunaan minarex $A, B, C$ dan $D$ dapat dilihat dalam tabel 2, 3, 4 dan 5 .

Dari tabel 2, 3, 4 dan 5 semua hasil uji vulkanisat kompon memenuhi persyaratan mutu SNI 0778-89-A ; sol karet cetak untuk sepatu kanvas dan SNI 1844-990-A; Sol karet cetak sepatu olah raga, kecuali untuk ketahanan kikis sol sepatu untuk olah raga yang syarat mutunya maksimum $1,00 \mathrm{~mm}^{3}$ / $\mathrm{kgm}$ dimana basil uji vulkanisat kompon terendah adalah $1,52 \mathrm{~mm}^{3} / \mathrm{kgm}$ pada penggunaan $5 \mathrm{phr}$ minarex $\mathrm{C}$ type 3 dan berat jenis vulkanisat kompon untuk penggunaan minarex A.2 hampir semua hasil uji tidak memenuhi 
syarat mutu untuk sepatu kanvas umum yang ditetapkan maks. 1,50 dengan hasil uji 1,62-1,88 gr/ $/ \mathrm{cm}^{3}$. Sedangkan hasil uji kompon yang menggunakan minarex C dan Minarex D hampir semua memenuhi syarat mutu sepatu olah raga dari kanvas yang ditetpakan maks. $1,30 \mathrm{gr} / \mathrm{cm}^{3}$ dimana haisl uji 1,27. $1,31 \mathrm{gr} / \mathrm{cm}^{3}$

Dibandingkan dengan persyaratan mutu sepatu kanvas yang ditentukan oleh Standar Korea (KS M) dan China (CSN) yang hanya menentukan syarat mutu kekuatan tarik dan perpanjangan putus maka hasil uji vulkansiat kompon jauh lebih baik dari persyaratan yang ditentukan (lihat tabel 7).

Dari beberapa penelitian yang dilakukan untuk sol sepatu kanvas umum maupun sol sepatu olah raga dari karet yang menggunakan minyak pelunak jenis lain yang menghasilkan sifat ketahanan kikis yang juga tidak memenuhi persyaratan mutu dalam SNI, sedangkan sifat fisis lainnya memenuhi persyaratan mutu. Seperti penggunaan napthanic oil $2 \mathrm{phr}$ sebagai bahan pelunak menghasilkan ketahanan kikis 1,43-2,04 mm $/ \mathrm{kgm}$ (Soepranoto 1987) dan penggunaan napthanic oil 6-10 phr menghasilkan ketahanan kikis $1,6715-2,7939 \mathrm{~mm}^{3} / \mathrm{kgm}$ (Titien Sayekti, 1990). Sedangkan hasil uji sol karet tak untuk sepatu olah raga yang ada di pasaran yang dihasilkan oleh beberapa pabrik, ketahanan kikisnya antara 1,6899-2,1219 $\mathrm{mm}^{3} / \mathrm{kgm}$ (Usodo, 1989).

Berdasarkan hasil data uji penelitian yang dilakukan dan dibandingkan dengan hasil penelitian yang dilakukan oleh beberapa peneliti yang menggunakan bahan pelunak impor dibandingkan penggunaan Minarex Pertamina untuk bahan pelunak dapat disimpulkan penggunaan minarex dalam pembuatan kompon sol sepatu kanvas yang mempunyai mutu yang sama dengan bahan pelunak impor.

3. Pengaruh minarex terhadap sifat fisis kompon.

Menurut Ridha-1990, bahan pelunak tidak bereaksi secara kimia dengan karet, tetapi berpengaruh terhadap sifat-sifat kompon atau barang jadi karet. Bahan pelunak berfungsi sebagai pelemas antar molekul atau partikel yang akan memberikan kenaikan dan penurunan sifat fisis kompon.

Dari hasil uji sifat fisis kompon yang menggunakan minarex yang bervariasi antara $2-8 \mathrm{phr}$ jenis dan type lihat tabel 2,3,4 dan 5 setelah dilakukan analisa statistik metoda faktorial menghasilkan sebagai berikut :

a. Penambahan 2-8 phr minarex dengan jenis yang berbeda akan mengha- silkan sifat kekuatan tarik dan ketahanan sobek, perpanjangan putus, perpanjangan tetap, kikis, kekerasan dan herat jenis vulkanisat kompon yang berbeda atau mempunyai hubungan yang sangat nyata pada $P \leq$ 0,01 Sifat fisis vulkanisat kompon makin besar/tinggi menurut jenis yaitu: Minarex $\mathrm{D}>\mathrm{C}>\mathrm{B}>\mathrm{A}>$ untuk kekuatan tarik, ketahanan sobek, perpanjangan putus, perpanjangan tetap, kikis, kekerasan dan berat jenis yang semakin besar.

b. Penambahan $2-8$ phr minarex dengan type yang berbeda akan menghasilkan sifat kekuatan sobek, kikis, kekerasan dan berat jenis vulkanisat kompon yang berbeda atau mempunyai hubungan yang sangat nyata pada $\mathrm{P} \leq 0,01$

c. Penambahan 2-8 phr minarex dengan periakuan yang berbeda mempegaruhi sifat perpanjangan putus, perpanjangan tetap $50 \%$ dan kekesan ven atau tidak mempunyai hubungan yang sangat nyata pada $P \leq 0,01$

\section{KESIMPULAN}

Berdasarkan percobaan yang dilakukan ternyata minarex yang diproduksi Pertamina dapat digunakan untuk bahan pelunak dalam pembuatan kompon sol karet untuk sepatu kanvas karena :

1. Tingkat kecocokan bahan pelunak minarex dengan karet sangat baik ini ditandai dengan tidak adanya pengeluaran minyak kepermukaan kompon dan vulkanisat kompon.

2. Semua hasil uji vulkanisat yang menggunakan pelunak minaarex $2-8 \mathrm{phr}$ memenuhi SNI yaitu maksimum $1,00 \mathrm{~mm} 3 / \mathrm{kgm}$ dibandingkan dengan hasil penelitian paling rendah $1,52 \mathrm{~mm}^{3} / \mathrm{kgm}$ dan tertinggi $2,35 \mathrm{~mm}^{3} / \mathrm{kgm}$ dan berat jenis vulkanisat kompon'yang menggunakan A dan Minarex B tidak memenuhi syarat mutu untuk sepatu kanvas olah raga dengan syarat maks. $1,30 \mathrm{gr} / \mathrm{cm}^{3}$ dibandingkan dengan hasil uji $1,31-1,88 \mathrm{gr} / \mathrm{cm}^{3}$.

3. Pengaruh penambahan bahan pelunak minarex terhadap sifat fisis kompon karet mempunyai hubungan sangat nyata jenis minarex terhadap kekuatan 
tarik, perpanjangan putus, perpanjangan tetap, kikis, kekerasan dan berat jenis dan ketahanan sobek vulkanisat kompon. Sedangkan type minarex mempunyai hubungan yang nyata dengan ketahanan sobek, kekerasan, kikis dan berat jenis vulkanisat kompon dan perlakuan minarex $2-8 \mathrm{phr}$ mempunyai hubungan yang nyata dengan perpanjangan putus, perpanjangan tetap dan kekerasan vulkanisat kompon.

\section{DAFTAR PUSTAKA}

1. Ena Sutrisna W. Processing oil Pertamina sebagai bahan penunjang dalam pengembangan produksi barang karet, Proceeding Pertemuan Teknis Pengembangan Produksi barang Karet, BBKKP, Yogyakarta, 25 Pebruari 1992

2. Endin, ZA Proses Pembuatan, Kemampuan Produksi dan Reliability of supply Processing Oil Kilang Cilacap, Proseeding Lokakarya Pro-

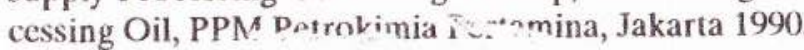

3. Kisha Surya Bhuana dan Agustinus Soemadi, Study Perbandingan Penggunaan Processing Oil Pertamina dan Dutrex sebagai minyak Proses Dalam Pembuatan Kompon Telapak Ban dan Bantalan Jambatan, Proceeding Lokakarya Proceessing Oil, PPM Petrokimia, Jakarta 1990.

4. Morton, Mauricia, Rubber Technology, Reinhald Publishing Corporation, New York, 1963.

5. Ridha Arizal, DR, M.Sc. Pengaruh Hasil Analisa Kimia Bahan Pelunak Minyak Terhadap Kompon dan Vulkansiat Karet, Proceeding Lokakarya Processing Oil, PPM Petrokimia Pertamina Jakarta 1990 .

6. Suparman, Ir., Cara Pengujian dan Analisa Processing Oil Laboratorium Pertamina UP-IV, Proceeding Lokakarya Processing Oil, PPM Petrokimia Pertamina, Jakarta 1990.

7. Socpranoto. Drs dkk. Penclitian Pebuatan Kompon Karet untuk Sol dan Foxing Scpatu Kanvas, BBKKP, Yogyakarta, 1987.
8. Sofyan Karani, dkk. Penelitian Penggunaan Paraffinic oil Pertamina sebagai Minyak Pelunak Kompon Karat untuk Sol Sepatu Kanvas, majalah barang Kulit, Karet dan Plastik, Vol. VIII No. 15 tahun 1992/ 1993, BBKKP, Yogyakarta.

9. Suwarti Suseno, RS., DR.Ir, Manfaat bahan Pembantu Produk Dalam Negeri untuk Industri Karet, Proceeding Lokakarya Processing Oil, PPM Petrokimia Pertamina, Jakarta, 1990.

10. Titien Sayekti, Ir dkk, Penelitian Kompon Sol Karet Cetak sepatu Kanvas Untuk olah raga, Proceeding Pertemuan Teknis Perkembangan Produk Karet, BBKKP Yogyakarta, 1991.

11. Usodo, B.Sc. dil. Penelitian Pengaruh Cuaca Terhadap Sol Karet Cetak Sepatu Olah raga dengan WOM dan Cuaca Udara Luar, BBKKP, Yogyakarta 1989. 
bel 2. Hasil uji rata-rata sifat fisis vulkanisat kompon karet yang menggunakan minarex $\mathrm{A}$

\begin{tabular}{|c|c|c|c|c|c|c|c|c|}
\hline \multirow{2}{*}{ Pengujian } & \multicolumn{2}{|c|}{ Persyaratan SNI } & \multicolumn{3}{|c|}{ Minarex A.2 (phr) } & \multicolumn{3}{|c|}{ Minarex A.3 (phr) } \\
\hline & 1844-90-A & 0778-89-A & 2 & 5 & 8 & 2 & 5 & 8 \\
\hline $\begin{array}{l}\text { kuatan Tarik, } \\
\mathrm{mm}^{2}\end{array}$ & $\min .10$ & $\min .4,90$ & 13,64 & 13,45 & 12,52 & 12,65 & 13,64 & 11,11 \\
\hline $\begin{array}{l}\text { erpanjangan } \\
\text { urus, \% }\end{array}$ & $\min .250$ & $\min .100$ & 490 & 447 & 417 & 320 & 460 & 53 \\
\hline $\begin{array}{l}\text { erpanjangan } \\
\text { tap } 50 \%, \%\end{array}$ & $\mathrm{mal}$ & mak & 1,41 & 1,55 & 1,51 & 1,43 & 1,89 & 1, \\
\hline $\begin{array}{l}\text { ekuatan Sobek, } \\
1 / \mathrm{mm} 2\end{array}$ & $\min .5,80$ & $\min .2,45$ & 5,91 & 5,76 & 5,48 & 5,13 & 5,70 & 10,3 \\
\hline ekerasan, shore A & $50-70$ & $55-75$ & 63,00 & 62,33 & 60,67 & 62,67 & 61,3 & 59,33 \\
\hline $\begin{array}{l}\text { etahanan kikis, } \\
\mathrm{m} 3 / \mathrm{kgm}\end{array}$ & maks. 1,00 & maks. 2,50 & 1,73 & 1,68 & 1,85 & 2,12 & 2,27 & 2,0 \\
\hline obot jenis, gr/cm3 & maks. 1,30 & maks. 1,50 & 1,62 & 1,75 & 1,88 & 1,49 & 1,40 & 1,33 \\
\hline $\begin{array}{l}\text { etahanan reta } \\
\text { entur, } 250 \mathrm{kcs}\end{array}$ & & & $\begin{array}{l}\text { tidak } \\
\text { retak }\end{array}$ & $\begin{array}{l}\text { tidak } \\
\text { retak }\end{array}$ & & $\begin{array}{l}\text { tidak } \\
\text { retak }\end{array}$ & \begin{tabular}{|l|} 
tidak \\
retak
\end{tabular} & $\begin{array}{l}\text { tidak } \\
\text { retak }\end{array}$ \\
\hline
\end{tabular}

bel 3. Hasil uji rata-rata sifat fisis vulkanisat kompon karet yang menggunakan minarex $B$

\begin{tabular}{|c|c|c|c|c|c|c|c|c|}
\hline \multirow{2}{*}{ Pengujian } & \multicolumn{2}{|c|}{ Persyaratan SNI } & \multicolumn{3}{|c|}{ Minarex A.2 (phr) } & \multicolumn{3}{|c|}{ Minarex A.3 (phr) } \\
\hline & 1844-90-A & 0778-89-A & 2 & 5 & 8 & 2 & 5 & 8 \\
\hline $\begin{array}{l}\text { ekuatan Tarik, } \\
1 / \mathrm{mm}^{2}\end{array}$ & $\min .10$ & $\min .4,90$ & 11,26 & 9,99 & 12,13 & 12,13 & 11,66 & 9,12 \\
\hline $\begin{array}{l}\text { rpanjangan } \\
\text { rus, \% }\end{array}$ & $\min .250$ & $\min .100$ & 450 & 410 & 466 & 353 & 428 & 521 \\
\hline $\begin{array}{l}\text { erpanjangan } \\
\text { tap } 50 \%, \%\end{array}$ & maks. 4,00 & maks. 10,0 & 2,33 & 2,00 & 1,44 & 1,89 & 1,62 & 1,46 \\
\hline $\begin{array}{l}\text { Sekuatan Sobek, } \\
\mathrm{J} / \mathrm{mm} 2\end{array}$ & $\min .5,80$ & $\min .2,45$ & 7,28 & 3,85 & 4,40 & 7,00 & 3,92 & 4,13 \\
\hline ekerasan, shore A & $50-70$ & $55-75$ & 64,00 & 61,33 & 57,33 & 55,67 & 65,33 & 61,67 \\
\hline $\begin{array}{l}\text { Setahanan kikis, } \\
\mathrm{nm} 3 / \mathrm{kgm}\end{array}$ & maks. 1,00 & maks. 2,50 & 1,98 & 1,80 & 2,03 & 1,95 & 2,28 & 2,21 \\
\hline 3obot jenis, $\mathrm{gr} / \mathrm{cm} 3$ & maks. 1,30 & maks. 1,50 & 1,46 & 1,41 & 1,36 & 1,40 & 1,35 & 1,31 \\
\hline $\begin{array}{l}\text { ahanan retak } \\
\text { tur, } 250 \mathrm{kcs}\end{array}$ & $\begin{array}{l}\text { tidak } \\
\text { retak }\end{array}$ & $\begin{array}{l}\text { tidak } \\
\text { retak }\end{array}$ & \begin{tabular}{|l|} 
tidak \\
retak
\end{tabular} & \begin{tabular}{|l|} 
tidak \\
retak \\
\end{tabular} & \begin{tabular}{|l|} 
tidak \\
retak \\
\end{tabular} & \begin{tabular}{|l|} 
tidak \\
retak
\end{tabular} & \begin{tabular}{|l|} 
tidak \\
retak
\end{tabular} & $\begin{array}{l}\text { tidak } \\
\text { retak }\end{array}$ \\
\hline
\end{tabular}

Tabel 4. Hasil uji rata-rata sifat fisis vulkanisat kompon karet yang menggunakan minarex C

\begin{tabular}{|c|c|c|c|c|c|c|c|c|}
\hline \multirow{2}{*}{ Pengujian } & \multicolumn{2}{|c|}{ Persyaratan SNI } & \multicolumn{3}{|c|}{ Minarex A.2 (phr) } & \multicolumn{3}{|c|}{ Minarex A.3 (phr) } \\
\hline & 1844-90-A & 0778-89-A & 2 & 5 & 8 & 2 & 5 & 8 \\
\hline $\begin{array}{l}\text { Kekuatan Tarik, } \\
\mathrm{N} / \mathrm{mm}^{2}\end{array}$ & $\min .10$ & $\min .4,90$ & 12,78 & 17,95 & 14,61 & 17,65 & 14,42 & 18,79 \\
\hline $\begin{array}{l}\text { Perpanjangan } \\
\text { purus, \% }\end{array}$ & $\min .250$ & $\min .100$ & 530 & 655 & 565 & 602 & 537 & 773 \\
\hline $\begin{array}{l}\text { Perpanjangan } \\
\text { tetap } 50 \%, \%\end{array}$ & maks. 4,00 & maks. 10,0 & 1,20 & 2,81 & 1,40 & 2,19 & 2,43 & 1,48 \\
\hline $\begin{array}{l}\text { Kekuatan Sobek, } \\
\mathrm{N} / \mathrm{mm} 2\end{array}$ & $\min .5,80$ & $\min .2,45$ & 7,07 & 12,83 & 11,37 & 14,70 & 12,51 & 13,73 \\
\hline Kekerasan, shore A & $50-70$ & $55-75$ & 59,67 & 64,67 & 59,67 & 69.67 & 68,00 & 64,33 \\
\hline $\begin{array}{l}\text { Ketahanan kikis, } \\
\mathrm{mm} 3 / \mathrm{kgm}\end{array}$ & maks. 1,00 & maks. 2,50 & 2,04 & 1,94 & 1,83 & 1,96 & 1,52 & 1,54 \\
\hline Bobot jenis, gr $/ \mathrm{cm} 3$ & maks. 1,30 & maks. 1,50 & 1,27 & 1,31 & 1,34 & 1,28 & 1,29 & 1,28 \\
\hline $\begin{array}{l}\text { Ketahanan retak } \\
\text { lentur, } 250 \mathrm{kcs}\end{array}$ & $\begin{array}{l}\text { tidak } \\
\text { retak }\end{array}$ & $\begin{array}{l}\text { tidak } \\
\text { retak }\end{array}$ & $\begin{array}{l}\text { tidak } \\
\text { retak }\end{array}$ & $\begin{array}{l}\text { lidak } \\
\text { retak }\end{array}$ & $\begin{array}{l}\text { tidak } \\
\text { retak }\end{array}$ & $\begin{array}{l}\text { tidak } \\
\text { retak }\end{array}$ & $\begin{array}{l}\text { tidak } \\
\text { retak }\end{array}$ & $\begin{array}{l}\text { tidak } \\
\text { retak }\end{array}$ \\
\hline
\end{tabular}

Tabel 5. Hasil uji rata-rata sifat fisis vulkanisat kompon karet yang menggunakan minarex D

\begin{tabular}{|c|c|c|c|c|c|c|c|c|}
\hline \multirow{2}{*}{ Pengujian } & \multicolumn{2}{|c|}{ Persyaratan SNI } & \multicolumn{3}{|c|}{ Minarex A.2 (phr) } & \multicolumn{3}{|c|}{ Minarex $\Lambda .3(\mathrm{phr})$} \\
\hline & $1844-90-\mathrm{A}$ & 0778-89-A & 2 & 5 & 8 & 2 & 5 & 8 \\
\hline $\begin{array}{l}\text { Kekuatan Tarik, } \\
\mathrm{N} / \mathrm{mm}^{2}\end{array}$ & $\min .10$ & $\min .4,90$ & 20,10 & 19,88 & 20,33 & 21,82 & 22,34 & 19,56 \\
\hline $\begin{array}{l}\text { Perpanjangan } \\
\text { purus, } \%\end{array}$ & $\min .250$ & $\min .100$ & 741 & 670 & 760 & 662 & 691 & 701 \\
\hline $\begin{array}{l}\text { Perpanjangan } \\
\text { tetap } 50 \%, \%\end{array}$ & maks. 4,00 & maks. 10,0 & 1,84 & 1,91 & 2,01 & 2.40 & 2,54 & 2,22 \\
\hline $\begin{array}{l}\text { Kekuatan Sobek, } \\
\mathrm{N} / \mathrm{mm} 2\end{array}$ & $\min .5,80$ & $\min .2,45$ & 13,60 & 13,22 & 14,26 & 14,67 & 13,64 & 14,29 \\
\hline Kekerasan, shore A & $50-70$ & $55-75$ & 67,00 & 63,33 & 61,00 & 67,33 & 64,33 & 60,67 \\
\hline $\begin{array}{l}\text { Ketahanan kikis, } \\
\mathrm{mm} 3 / \mathrm{kgm}\end{array}$ & maks. 1,00 & maks. 2,50 & 1,78 & 1,89 & 2,06 & 2,35 & 1,83 & 2,10 \\
\hline Bobot jenis, gr/cm3 & maks. 1,30 & maks. 1,50 & 1,30 & 1,28 & 1,29 & 1,28 & 1,29 & 1,29 \\
\hline $\begin{array}{l}\text { Ketahanan retak } \\
\text { lentur, } 250 \mathrm{kcs}\end{array}$ & $\begin{array}{l}\text { tidak } \\
\text { retak }\end{array}$ & $\begin{array}{l}\text { tidak } \\
\text { retak }\end{array}$ & $\begin{array}{l}\text { tidak } \\
\text { retak }\end{array}$ & $\begin{array}{l}\text { tidak } \\
\text { retak }\end{array}$ & $\begin{array}{l}\text { tidak } \\
\text { retak }\end{array}$ & $\begin{array}{l}\text { tidak } \\
\text { retak }\end{array}$ & $\begin{array}{l}\text { tidak } \\
\text { retak }\end{array}$ & $\begin{array}{l}\text { tidak } \\
\text { retak }\end{array}$ \\
\hline
\end{tabular}

Vol. X No. 19 Tahun 1993/1994 
Tabel 6. Persyaratan mutu sol sepatu dari beberapa negara

\begin{tabular}{|c|c|c|c|c|c|c|}
\hline \multirow{3}{*}{ No. } & \multirow{3}{*}{ Test item } & \multicolumn{3}{|c|}{ CNS 68531} & \multicolumn{2}{|c|}{ KS.M $6522-74$} \\
\hline & & \multirow{2}{*}{$\begin{array}{l}742 . \mathrm{S}: \\
2009\end{array}$} & \multicolumn{2}{|c|}{ 743.S.2010 } & \multirow[b]{2}{*}{ Soft } & \multirow[b]{2}{*}{ Hard } \\
\hline & & & $\begin{array}{c}\text { all } \\
\text { numbers }\end{array}$ & large & & \\
\hline 1 & $\begin{array}{l}\text { Tensite strength, } \\
\mathrm{kg} / \mathrm{mm} 2\end{array}$ & $\begin{array}{l}\min \\
65\end{array}$ & $\min _{90}$ & $\begin{array}{c}\min \\
150\end{array}$ & $\min$. & $\begin{array}{c}\min . \\
60\end{array}$ \\
\hline & $\mathrm{N} / \mathrm{mm} 2$ & 6,37 & 8,83 & 14,71 & 5,88 & 5,88 \\
\hline 2 & Fiengation, \% & $\begin{array}{l}\min . \\
330\end{array}$ & $\min _{150}$ & $\frac{\min }{450}$ & $\begin{array}{l}\min \\
300\end{array}$ & - \\
\hline 3 & $\begin{array}{l}\text { Aging resistance } \\
\text { property, \% }\end{array}$ & - & - & - & $\begin{array}{c}\text { maks. } \\
20\end{array}$ & $\begin{array}{l}\text { maks. } \\
20\end{array}$ \\
\hline
\end{tabular}

Keteringan :

(NS $60531-742$ S.2009: Testing standard for sportshoes. ( NS6453)-743.S2010): Testing standard for sport shoes. (canvas shoes with rubber sole)
KS $1+272-74$
: Canvas shoes with rubber sole 